\title{
Regeneration of the Completely Excised Gastro- cnemius Muscle in the Frog and Rat from Minced Muscle Fragments'
}

\author{
BRUCE IM. CARLSON \\ Department of Anatomy, The University of Michigan, \\ Ann Arbor, Michigan
}

\begin{abstract}
In 85 frogs and 29 rats, the entire gastrocnemius muscle was removed. After removal of as much connective tissue as possible, about two-thirds of the remaining muscle was finely minced with a scissors. These minced fragments were orthotopically re-implanted, and the overlying skin was sutured. As the implanted muscle fragments degenerate, new muscle fibers appears in the regenerate. The proportion of connective tissue to muscle is usually greater than normal, especially in the frog. Grossly, normal relationships are established with the cut ends of the Achilles and proximal tendons, as well as with the blood vessels and nerves. The total diameter of the regenerated muscle is almost always less than half of that seen in normal muscles. Regeneration of muscle is much more extensive in the rat than in the frog, and it occurs almost twice as rapidly. The histology of the regenerative process is described for both the frog and the rat.
\end{abstract}

Regeneration is a term which encompasses a number of distinctly different processes leading to the restoration of a missing part or to the duplication of a structure which is already present. The extent of regeneration may range from the restoration of an entire limb to the healing of relatively small defects in individual tissues or organs. Limb regeneration is considered to be an epimorphic process, occurring in a morphogenetic field and guided and controlled by a complex series of events involving the cooperation of nerves, the apical epidermis and other less well studied factors. In vertebrates the capacity for limb regeneration is highest in urodele amphibians and in premetamorphic anurans, but limb regeneration occurs sporadically and abortively in adult anurans and certain lizards. In higher vertebrates there has been little published evidence of limb regeneration. A certain degree of restoration of limb regeneration has been induced in adult anura by experimental means such as severe mechanical trauma (Polezhaev, '46), chemical irritation (Rose, '45), supplemental innervation (Singer, '54) and implantation of additional adrenal tissue (Schotte and Wilbur, '58).

Regeneration of tissue defects has been studied more extensively in higher verte- brates, and in almost all cases individual tissues have been shown to have the capacity to repair small defects (McMinn, '67).

An area which has received considerably less attention than it deserves is the regeneration of relatively massive amounts of tissue components of extremities or other organs. One of the most striking examples of this type of regeneration was uncovered by Studitsky ('59), who devised a method for obtaining relatively great amounts of skeletal muscle regeneration as well as the restoration of external form of certain muscles by completely removing the muscle, mincing it and reimplanting the fragments. Although this work has been widely discussed in the Soviet Union, it is little recognized elsewhere. The purpose of the experiments reported in this paper is to confirm the results of Studitsky on regeneration of the gastrocnemius muscle in the rat and to compare this type of muscle regeneration in two widely differing species, the frog and the rat.

\section{MATERIALS AND METHODS}

Eighty-five frogs (Rana pipiens) obtained from Minnesota, Wisconsin and Michigan

1 Suported in part by Institutional Research grant IN-40H to the University of Michigan from the American Cancer Society. 
and 29 rats (Wistar and mixed strains) were used in these experiments.

Series $A$. After anesthetization of a frog in 1:1000 MS 222, a skin incision was made from the popliteal area to the heel. The gastrocnemius muscle was defined, the superficial tibial nerve was dissected free from its location in the epimysium and the Achilles tendon was cut at a level which ensured that no muscle fibers remained (fig. 1a). Then with traction applied to the free distal end of the muscle, the nerve to the gastrocnemius was dissected as far into the muscle as possible and then cut. Not infrequently moderate bleeding occurred as the artery accompanying the nerve was severed. Proximally the gastrocnemius is attached to the femur in two places. The tendinous connection (fig. 1b) was cut next. Finally the less well-defined proximal attachment (fig. 1c) was cut next to the bone with microdissecting scissors. As this last step was being performed, small nerve branches entering the most proximal part of the gastrocnemius muscle were preserved insofar as possible. Examination of frogs killed at this point in the operation showed that no residual muscle fibers remained after this procedure. The removed gastrocnemius was placed in $0.6 \% \mathrm{NaCl}$ and as much grossly visible connective tissue as possible

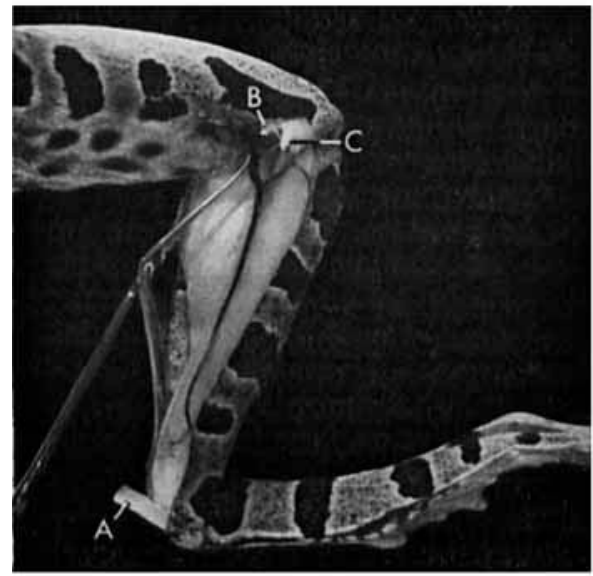

Fig. 1 Rana pipiens after removal of the gastrocnemius muscle. Letters $a, b$, and $c$ refer to the cut tendons to which the muscle was attached (see text). The hook at the left is pulling the tibial nerve. was cut away. The remaining muscle was then minced with a scissors until the fragments averaged about one $\mathbf{m m}$ in diameter. About two-thirds to three-fourths of this minced muscle was replaced into the space originally occupied by the removed muscle (fig. 2). Larger quantities of implant material were found to increase post-operational complications such as excessive edema and splitting of sutures. Aside from arranging the muscle fragments so that they were evenly distributed throughout the space, no other precautions were taken to hold the fragments in place. The skin incision was then closed with 6-0 silk sutures placed about 1-2 mm apart. Aside from soaking instruments in $70 \%$ alcohol, no sterile precautions were taken. Following the operation, each frog was returned to an individual container and maintained at temperatures from 23-26 degrees. In other experiments to be reported later, this technique has been performed on Rana clamitans and $R$. catesbiena with essentially the same results.

As controls, removal of the gastrocnemius was performed on ten frogs, but nothing was replaced into the limb prior to suturing the skin.

Series B. In an additional experiment, conducted upon 15 frogs, the distal half

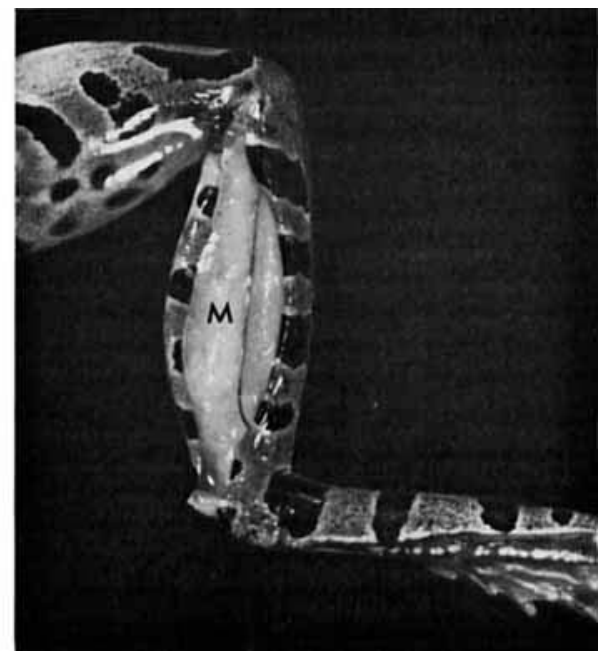

Fig. 2 The same frog as in figure 1 after replacement of the minced muscle fragments $(\mathrm{m})$. Nothing is used to hold them in place except the skin which is sutured over the implant. 
of the gastrocnemius was removed, minced as above and re-implanted. Controls (ten animals ) consisted of removal of the distal half of the muscle without replacement. This operation did not disturb the nerve supply to the muscle.

Rat operations were performed on animals of both sexes whose weights ranged from 65-100 gm. The operative technique was essentially the same as that described by Studitsky et al. ('57). Semi-sterile conditions, consisting of boiling istruments and glassware and washing the skin with $70 \%$ alcohol, were found to be adequate. The rats were anesthetized by intraperitoneal injections of sodium pentobarbital (5-7 mg/100 gm). After the right leg was shaved and washed in alcohol, a skin incision was made over the length of the gastrocnemius muscle. Due to the greater amount of connective tissue in the rat, it was necessary to define major structures by blunt dissection. The biceps femoris was then transacted in the area overlying the gastrocnemius. The sural nerve was dissected free from the surrounding tissue, and the connective tissue surrounding the Achilles tendon was dissected away. In order to obtain a field free of cut muscle fibers in the rat, not only the gastrocnemius, but also the soleus and plantaris muscles were removed. The tendons of all three muscles merge into the Achilles tendon, which was cut distal to the point of merging. At this level, no muscle fibers could be found in the remaining tendon. Next the plantaris muscle was cut loose at its proximal tendinous attachment. The gastrocnemius was then divided into lateral and medial portions at the site where it is pierced by the tibial nerve. It was easier to remove the lateral portion first. In most cases the proximal attachment of the lateral head was pierced by the peroneal nerve. This nerve was dissected free and preserved intact. Then the proximal attachment of the lateral head of the muscle was severed. Because of the deep location and poor visibility of this attachment, branches of the popliteal artery were occasionally cut. The ensuing hemorrhage was easily controlled with pressure. In some cases a few small fragments of muscle fibers were left attached to the bone. Although these were histologically observed to regenerate, their role in the entire restorative process was inconsequential. The medial portion of the gastrocnemius was removed with little difficulty. Like in the frog, all branches of nerves supplying the muscles were dissected free and preserved inasmuch as possible. Figure 3 shows the leg of a rat after complete removal of the jumping complex of muscles. The muscles were placed in $0.9 \%$ saline, the connective tissue was removed and the muscle tissue was minced in the same manner as described for the frog experiments. About two-thirds to three-fourths of the minced muscle was re-implanted into the leg (fig. 4 ), and the biceps femoris was sutured together (three or four stitches of 6-0 silk) over the proximal fragments (fig. 5). The overlying skin was then sutured, and

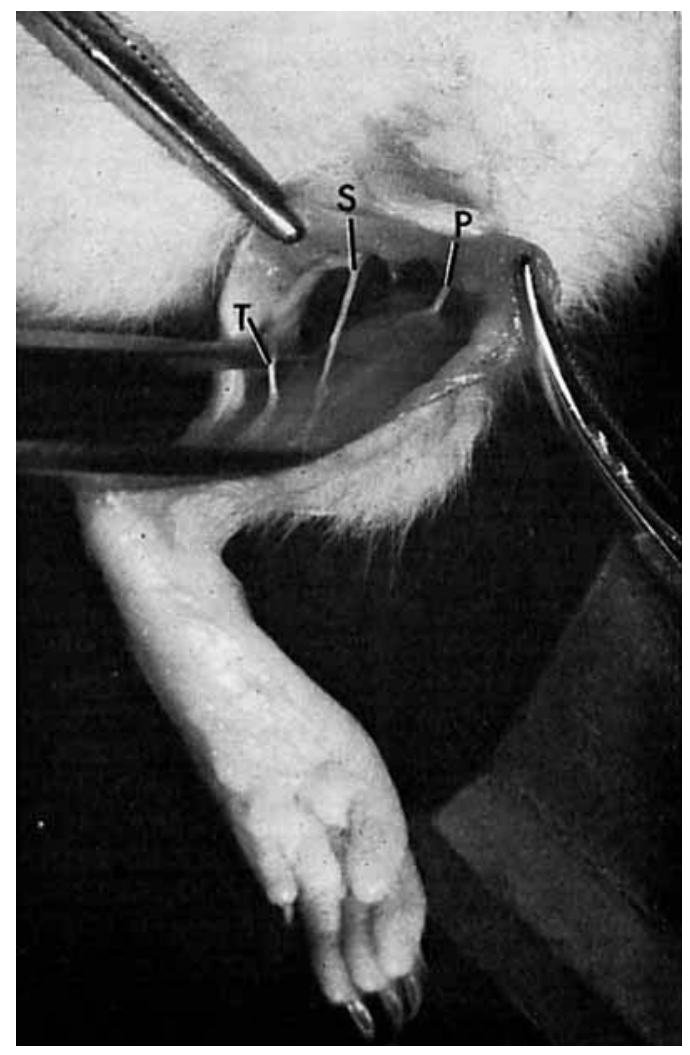

Fig. 3 Rat leg after removal of the gastrocnemius, soleus and plantaris muscles. The transected biceps femoris muscle is retracted on either side of the incision. The tibial $(t)$, sural $(s)$ and peroneal ( $p$ ) nerves remain intact. 


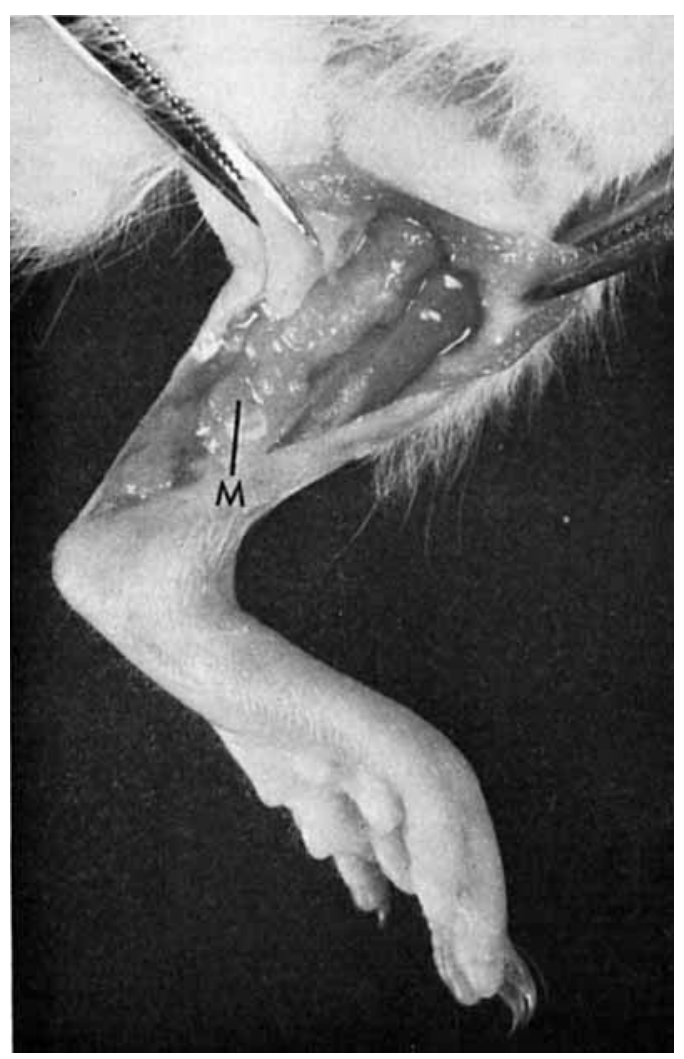

Fig. 4 Rat leg after minced muscle fragments $(m)$ have been replaced into the space left by the removed gastrocnemius muscle.

the skin was swabbed in $70 \%$ alcohol. The animals were then returned to their cages.

Of the first ten animals, some developed mild post-operational infections in the wounds. In subsequent cases the animals were given Cosa-Terramycin (Pfizer) in their drinking water ( $4 \mathrm{tsp} / \mathrm{gal}$ ) for seven days. No further infection resulted, and no interference with the gross or histological course of regeneration has been observed.

A control series, consisting of removal of the muscle in the manner described above but without replacement of any tissue, consisted of eight rats.

In the frog series animals were sacrificed at various intervals from one to 59 days after the operation. All animals were examined both grossly and microscopically. Rats were examined at intervals from two

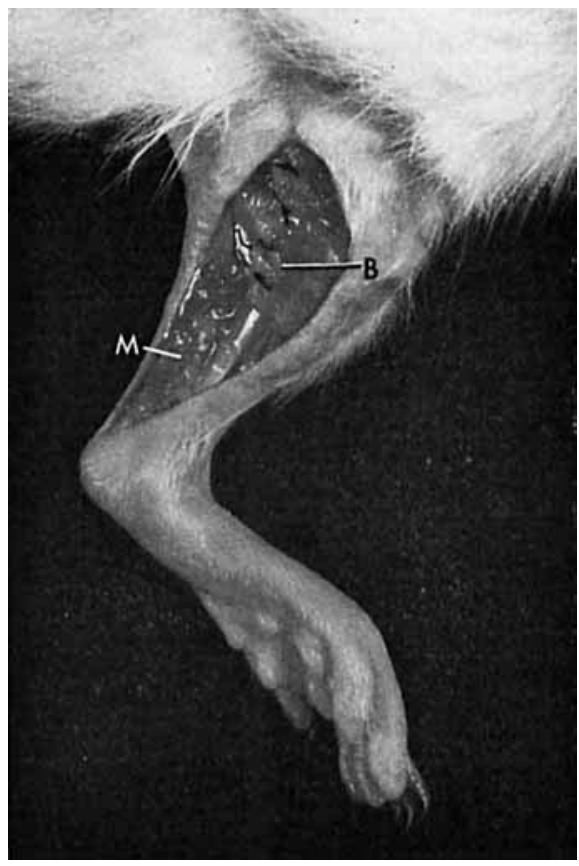

Fig. 5 Rat leg after the biceps femoris (b) has been sutured together over the proximal mass of muscle fragments $(m)$. The distal half of the implanted fragments $(m)$ is held in place by no structure other than the overlying skin.

to 45 days. In both rats and frogs, the regenerates were measured and sketched or photographed. Following this all were fixed in Bouin's, serially sectioned at $7 \mu$ and stained with hematoxylin and eosin or with Heidenhain's connective tissue stain.

\section{RESULTS}

\section{Frog series (Series A) - Controls}

In no case was any gross evidence of regeneration noted. The cut ends of the Achilles tendon and the proximal tendinous attachments were attached to the tissues immediately underlying them by bands of connective tissue (fig. 6). Histologically no muscle was seen in these bands.

Experimental - Gross course of regeneration. Externally the operated leg maintains a fairly normal form for the first two or three days after the operation. Starting with the fourth day, the leg frequently becomes edematous, a condition which may 


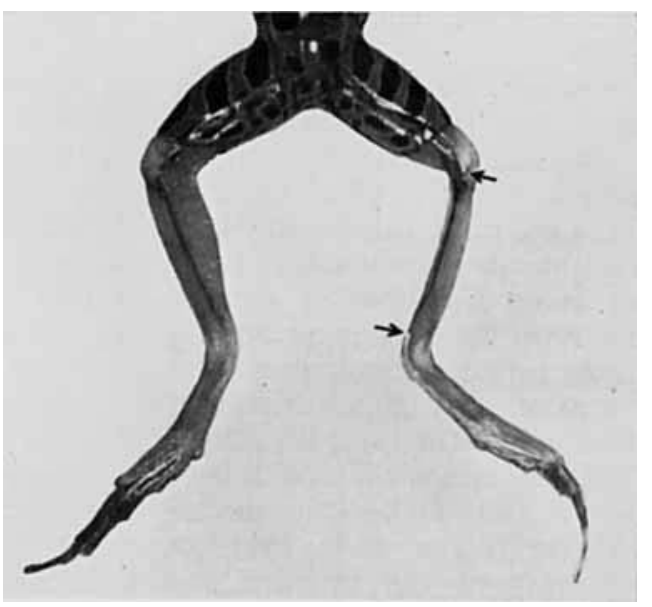

Fig. 6 Frog control (21 days). After complete removal of the gastrocnemius muscle without replacement, no continuity has been established between the cut tendons. Instead they are tightly adherent to the underlying tissues by means of connective tissue bands (arrows).

last through the sixth day. This period of edema is critical in terms of survival of the animal, and in frogs which were operated upon during the winter, large numbers died during this stage. By the end of the first week, the swelling subsides and the leg again assumes a normal appearance. During the second week the sutures fall out. From this time the operated leg gradually becomes thinner than the control.

Internally, the muscle fragments are loosely adherent to each other by the second day, and their overall form is roughly the same as that assumed by the originally implanted tissue. As the first week progresses, the implanted bits of muscle become more adherent, especially in the outer regions, and the form of the entire mass becomes molded so that the distal portion is more tapered than the proximal end. Distinct connections between the implanted mass and both the cut end of the Achilles tendon and the proximal tendons begin to form at the end of the first week. Within a couple of days these are firmly established. From this point the overall mass of the regenerate decreases until by the end of the second month the diameter of the regenerate is usually between $25 \%$ and $40 \%$ of the control muscle (fig. 7).

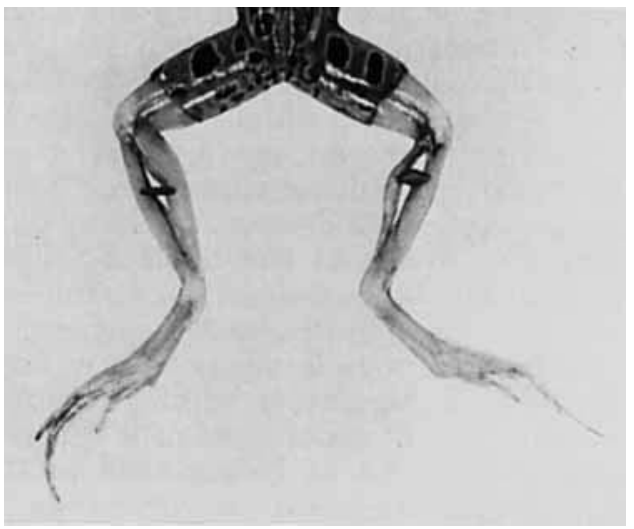

Fig. 7 Frog regenerate (18 days). Continuity has been established between the cut ends of the proximal and Achilles tendons. The diameter of this regenerate (right) is considerably less than that of the control muscle (left).

Despite the smaller than normal size, the regenerate establishes normal anatomical relationships with respect to proximal and distal tendon connections, nerve supply and usually vascular supply. Although normally the frog regenerates are not capable of any appreciable function, occasionally in this and in other experiments, spontaneous contractile activity has been quite pronounced.

Histological course of regeneration. Histologically the implanted tissue consists almost entirely of fragments of muscle fibers and the connective tissue sheaths which invest them. Small bits of dense connective tissue, nerves and blood vessels make up less than $5 \%$ of the total implanted mass.

Few cells of the host invade the implant during the first two or three days, and the general histological appearance does not greatly differ from the freshly implanted mass (fig. 10). Certain characteristic changes take place in the muscle fibers themselves. The sarcoplasm undergoes a hyaline and vacuolar type of degeneration. Although the myofibrils lose their regular parallel arrangement, patches of cross striations are usually visible after the sarcoplasmic degeneration is well underway. The most profound changes occur in the muscle nuclei. Early changes consist of a dispersal of irregularly granular chromatin throughout the nucleus, with 
increased concentrations lining the inside of the nuclear membrane. The small irregular granules then appear to condense into larger spherical units with no special distribution in the nucleus. In later stages only two of three dense chromatin spheres remain. These soon disappear, leaving only a negative image of the nucleus in the degenerating fiber. Several stages of nuclear degeneration are shown in figure 11.

Among the muscle fibers are erythrocytes, which degenerate within a couple of days. The amount of these cells depends upon the amount of hemorrhage at the time of the operation. Relatively small numbers of polymorphonuclear leukocytes, especially at the periphery of the implant, are also present initially. Like the erythrocytes, these soon degenerate, and their numbers are replaced by mononuclear cells midway in the first week. Concurrently, occasional primitive appearing fibroblasts can be seen among the degenerating muscle fibers.

At the end of the first week the first signs of regeneration can be demonstrated. Around the periphery of the implant the sarcoplasm of the muscle fibers has completely degenerated, leaving behind the endomysial tubes in which the first signs of actual muscle regeneration are seen. Among the degenerated muscle fibers are numerous spindle-shaped cells with large nuclei, one or two prominent nucleoli and basophilic cytoplasm (fig. 13). Although most of these cells are oriented roughly in accordance with the long axis of the implant, this is far from absolute at this stage. Mitotic activity of these cells is intense. Among these primitive cells are scattered mononuclear leukocytes and macrophages. An abundant capillary network is present in these peripheral regenerating areas. Inside the outer zone of regenerative activity, the muscle fragments and the composition of the host cells surrounding them has changed but little from the description given for the first few days after the operation.

The entire second week is characterized by an increase in the amount of peripheral regenerating tissue and a corresponding decrease in the amount of old muscle fragments in the central area (figs. 12, 14). During this time regeneration of both mus- cle fibers and connective tissue is taking place.

Early in the second week the primitive connective tissue cells are surrounded by a very fine meshwork of fibers which are stained with aniline blue. Initially the fibers are randomly oriented, but both they and the fibroblasts soon become stretched out along the lines of tension in the regenerate. As this is occurring, the fibroblasts become much more mature in appearance, and the amount of intercellular fibers is considerably increased.

Regeneration of new muscle itself follows a characteristic sequence of events. Because regeneration first occurs at the periphery of the implant and then progresses toward the interior, often several phases of muscle regeneration can be seen in the same tissue. As indicated by connective tissue staining, the early regenerative events occur inside the basement membrane and endomysium of the degenerating muscle fibers which were originally implanted. In the terminal stages of degeneration, the sarcoplasm of the old muscle fibers begins to break up, and at the same time macrophages and other mononuclear leukocytes appear in substantial numbers among the fragments. It is at this stage of degeneration that the first regenerating elements can be observed. Lining the inside of the basement membrane is a cuff of cells with relatively densely staining elongated nuclei. Seen in cross section, they are surrounded by a scanty, but intensely basophilic cytoplasm (figs. 15, 16). Although these cells are usually fairly regularly disposed about the basement membrane, preparations showing early stages of regeneration give no indication of continuity of these cells at the light microscopic level. Quite rapidly, however, the nuclei of these cells increase in size, and the chromatin becomes less condensed. The cytoplasm also increases in thickness but retains its intense basophilia. Along with this, peripheral cytoplasmic extensions come in contact with those of neighboring cells and appear to fuse (fig. 16). As this process is occurring, the remaining sarcoplasm of the original muscle fibers quickly disappears so that the regenerating structure consists of the original endomysium and basement mem- 
brane and a solid cuff of cells lining the inside of this tube, inside of which may be a loose aggregation of macrophages and mononuclear cells or only fluid (fig. 18). Once cytoplasmic fusion has occurred, the mass of certain regions of the resulting syncytial cuff increases considerably whereas other areas develop more slowly. The thickened regions generally contain masses of nuclei closely opposed to one another, as well as increased cytoplasm. The nuclei contain very prominent nucleoli. Subsequently the entire syncytial cuff increases in thickness and as a result obliterates the cavity left by the degenerated sarcoplasm of the original muscle fiber (fig. 19). This syncytial band has been called various names such as myosymplast, sarcoblast and myotube. In this paper it will be called a sarcoblast in accordance with the terminology used in the recent review by Betz et al. ('66).

One rather unusual feature of muscle regeneration in frogs is the rather consistent presence in the sarcoblasts of nuclei surrounded by a clear halo (figs. $17,19)$. These are most frequently seen in early sarcoblasts. Their origin and identity have not been determined, but the nuclei are usually surrounded by a rather thin rim of cytoplasm, and they resemble lymphocytes. These "halo" cells have rarely exhibited distinct mitotic figures while deeply embedded in the substance of the sarcoblast, and not infrequently cells of that description are seen in mitosis on the inner surface of the sarcoblast before the tube becomes solid. On the basis of their morphology and time of most frequent appearance, it may be that they represent mononuclear cells which have been trapped in the sarcoblastic tube as it solidifies. The fate of these cells has not been determined in these experiments, and it is not known, therefore, whether they are eventually incorporated into the regenerating muscle fibers or not.

As the tubular sarcoblast solidifies, its diameter decreases considerably from that of the original muscle fiber. In this stage, the nuclei are often densely packed and arranged in clumps with areas of cytoplasm in between. They soon, however, begin to spread out in the long chains so typical of regenerating muscle (figs. 20,
21). At this stage many of the nuclei show the deep indentations and constrictions often cited as evidence for their amitotic division (Altschul, '62). The cytoplasm is still very basophilic, but longitudinal myofibrillae are easily observed. The nucleocytoplasmic ratio is still very high. In succeeding days, the nuclei become arranged in very regular rows. Their size is large, the chromatin is vesicular, and the nucleoli are still large, but somewhat smaller than in previous stages. By 15 days the cytoplasm has increased in amount, and it is distinctly eosinophilic, but with a residual basophilic cast (fig. 21). In 18 day regenerates, the first cross striations in the muscle fibers can be clearly seen with Heidenhain's stain although they are not readily visible when stained with hematoxylin and eosin. The large nuclei are still centrally located, and the myofibrils are very well developed. Almost all traces of cytoplasmic basophilia are lost (fig. 22). At the start of the fourth week, some of the muscle nuclei are beginning to move from the central rows toward the periphery of the fibers, and the amount of sarcoplasm is greatly increased (fig. 23). From this time the regenerating muscle fibers increase in diameter, and the nuclei assume their normal position at the periphery of the fiber. Toward the end of the second month most of the muscle fibers are essentially mature although they may not yet have attained a normal diameter. In some cases, occasional fibers with nuclei still arranged in central rows may still be seen (fig. 24). As a rule the muscle fibers are arranged in a parallel array. Occasionally, however, muscle fibers with a quite mature histological appearance are ordered in a very irregular fashion (figs. 25, 26). The time sequence of the major events in muscle regeneration in the frog is compared with that of the rat in table 1 .

With respect to the regenerates as a whole, regenerating muscle fibers are fairly regularly scattered throughout from the time of their first appearance until midway in the third week. Starting at about the sixteenth day, just before the muscles would normally have become cross triated, varying numbers of them can be seen in stages of degeneration, characterized by nuclear pycnosis and cytoplasmic vacuoliz- 
TABLE 1

Comparison of events in muscle regeneration between the rat and frog according to day of first appearance

\begin{tabular}{clc} 
Frog & & Rat \\
\hline $6-7$ & $\begin{array}{l}\text { First appearance of well defined myoblasts inside } \\
\text { basement membrane of degenerating muscle fibers. }\end{array}$ & 2 \\
7 & Connections between regenerate and tendon stumps. & $3-5$ \\
8 & First appearance of multinucleated sarcoblasts. & 3 \\
$15-18$ & First appearance of cross striations. & 9 \\
$26+22$ & Disappearance of original muscle fragments. & 10 \\
\hline
\end{tabular}

ation. As a rule the degenerating muscle fibers have disappeared by the start of the fourth week, and from that time the regenerates are characterized by fields of dense, well developed connective tissue alternating with areas of maturing muscle fibers. The only recognizable traces of the original implant material consist of small pieces of dense connective tissue which were included along with the minced muscle fibers. In this series, the proportion of muscle to connective tissue ranged from one regenerate containing only dense fibrous connective tissue to others in which muscle fibers make up about $50 \%$ to $75 \%$ of the mass of the proximal portion of the regenerate. The distal third of these regenerates is always molded into dense connective tissue extensions of the Achilles tendon.

Series $B$. In control animals, the distal end of the muscle stump usually rounded up and became adherent to the underlying tissues by a thin strand of connective tissue. In one case, the Achilles tendon and distal end of the muscle stump were united by a thin strand of connective tissue which contained no muscle fibers. Regenerative changes were observed histologically in the cut ends of muscle fibers, but they were not extensive and did not increase the mass of the proximal segment of muscle.

Results in the experimental series differed little from those reported for series A. In fact it was somewhat surprising to observe that the proportion of muscle to connective tissue in the regenerates was usually less than that in regenerates formed after complete excision of the gas- trocnemius. Because of the similarity of these results with those of the previous series, no further consideration of them will be given here.

\section{Rat Series - Controls}

Of 8 animals in this series only one developed a thin band of connective tissue along the course of the tibial nerve. This contained no muscle fibers. In the other cases the Achilles tendon adhered to the underlying tissues (fig. 8).

Experimentals. Gross course of regeneration. Externally wound healing is rapid, and there is normally little evidence of inflammation. Although the rats typically remain quiet for the first day or two following the operation, they afterwards begin to move about in their cages. The foot on the operated side is usually dorsiflexed, and often the toes are flexed. During the first week or two weight is placed upon the calcaneal region, but later it is frequently shifted to the distal part of the foot. Although to inspection the operated leg appears very similar to the contralateral one, the decreased mass of the experimental limb can be readily determined by palpation.

Internally the implanted muscle fragments become loosely adherent shortly after the first day. Connections between the implant and the Achilles tendon and the normal origin of the gastrocnemius and plantaris are established between the third and fifth days. Toward the end of the first week and continuing until the start of the third, the mass of the regenerate decreases as the implanted muscle fibers 


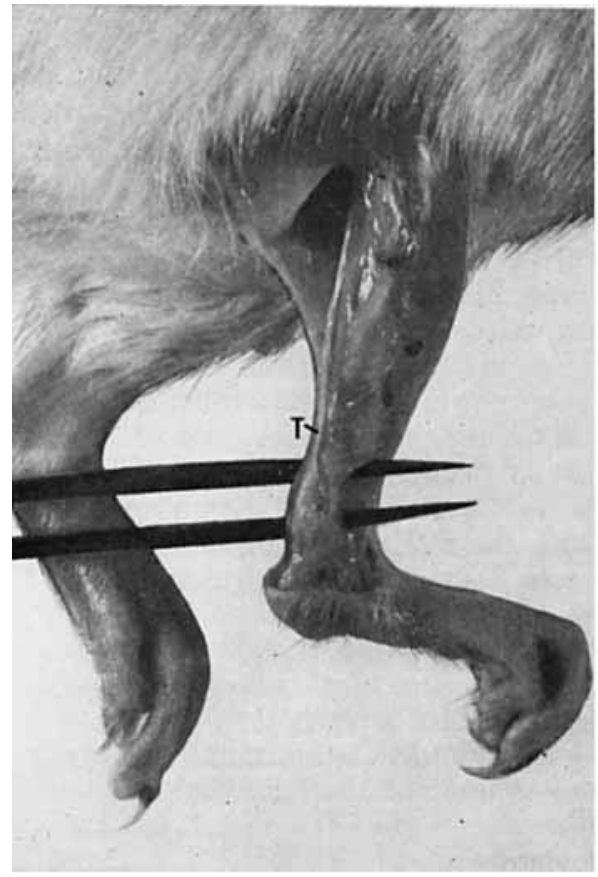

Fig. 8 Rat control (38 days). After removal of muscle without replacement of minced tissue, no continuity between proximal and distal cut tendons has occurred. Instead the Achilles tendon has become connected to the underlying tissues by a broad connective tissue adhesion. The tibial nerve $(t)$ is unaccompanied by any regenerated tissue.

are degenerating. At this time the diameter of the regenerate is about $35-40 \%$ of the contralateral muscle. As the regenerate matures, the distal portion becomes clearly tendinous in character whereas the proximal part assumes a muscular appearance (fig. 9). In the rat, connective tissue adhesions between the regenerate and surrounding tissues are quite frequent, much more so than in frogs. The gross relationships of the tibial, peroneal and sural nerves to the regenerate are close to normal.

Histological course of regeneration. Histologically the regenerative processes in the rat occur considerably more rapidly than they do in the frog. These differences are summarized in table 1 . The composition of the initial implant material is much like that used in the frog series except for a

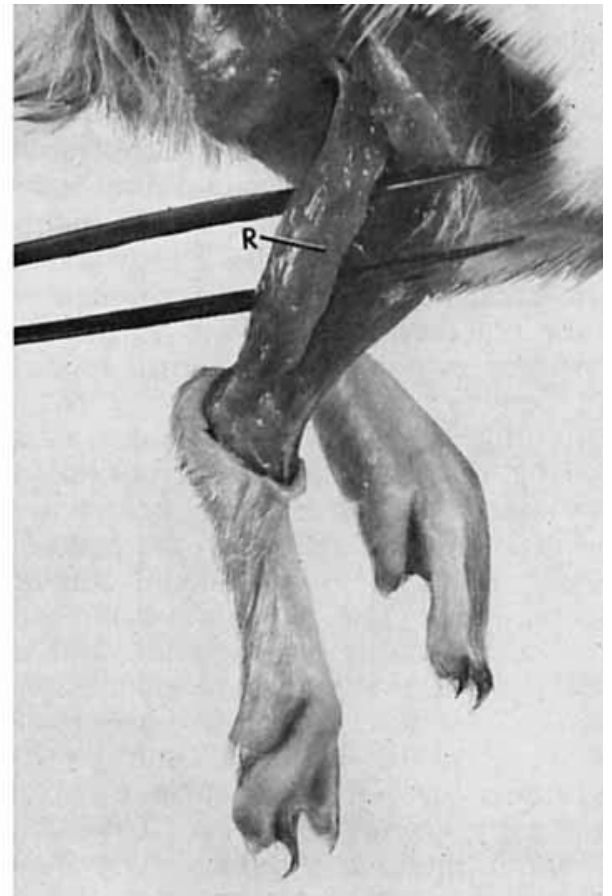

Fig. 9 Rat regenerate ( 32 days). The bulk of this regenerate $(r)$ is muscle. Distally it becomes more tendinous in appearance. The position of entry of the tibial nerve $(n)$ into the regenerate is approximately normal.

slightly lesser proportion of bits of dense connective tissue.

Both degeneration of old muscle and regeneration of new muscle fibers occur more rapidly than in the frog, so that by three days the histological picture is similar to that of a seven to nine day frog. Three days after the operation considerable peripheral degeneration of muscle fibers has occurred, and early stages of regeneration of new fibers are already apparent (fig. 27). Toward the interior of the implant, some areas of degenerating muscle are surrounded by moderately extensive pockets of polymorphonuclear leukocytes. In the periphery the basophilic, spindleshaped precursors of fibroblasts are already forming a part of the cellular architecture of the region. Mitotic figures among these cells are frequent. Most of the muscle regeneration is still in the early stages in which individual myoblasts appear to be fusing into syncytial cuffs lining the in- 
side of the basement membrane of the degenerating muscle fibers (fig. 28). Many of these hollow cylinders of newly regenerating muscle fibers contain macrophages. In a few areas, syncytial sarcoblasts are seen as solid structures containing rows of nuclei, some of which are deeply indented or creased (fig. 27). There is little evidence of a consistent spatial orientation of any of the regenerating elements at this time.

At five days there is intense regenerative activity at the periphery of the implant (fig. 29). As was demonstrated in the frog, there is a well defined gradient of regenerative stages from the center to the periphery of the implant. In the center the muscle fibers are in advanced stages of degeneration. The sarcoplasm in most fibers is beginning to fragment, and very little nuclear material is present in these fibers. Very few leukocytes are present among fibers in the most central region, and under low power the entire area takes on a very eosinophilic cast. Toward the periphery there is a fairly sharp border between the central eosinophilic zone and the outer basophilic zone. In this region are numerous areas in which the earliest stages of muscle regeneration can be found. Figure 30 illustrates such a region. Here one can see degenerating muscle fibers with basophilic cells beginning to encircle the inside of the basement membrane. Farther out toward the periphery the sarcoplasm of the original fibers has degenerated, leaving the typical syncytial basophilic cuff filled with macrophages and other mononuclear leukocytes. In the most peripheral regions, the regenerating muscle has already formed long sarcoblastic ribbons, often with several rows of nuclear chains (fig. 31). There is also a progressive increase in amount and maturity of new connective tissue elements from the center to the periphery. Although there is some linearity in the arrangement of the new muscle and connective tissue cells, their disposition is still a more accurate reflection of the position of the implanted fragments rather than of any tensions present in the regenerate.

By the end of the first week most of the distal portion of the regenerate consists of immature fibrous connective tissue. Proxi- mally, the last of the original muscle fibers can be seen in the center of the regenerate, while in the peripheral zones in the newly regenerating muscle fibers and connective tissue are becoming oriented parallel to the longitudinal axis of the limb (fig. 32). The more peripheral sarcoblasts have become markedly eosinophilic, and longitudinal myofibrillae are plainly seen. The connective tissue surrounding these fibers is in many places rather loosely organized and contains abundant macrophages and mononuclear leukocytes (fig. 33). At the boundry between the original degenerating muscle fibers and the newly regenerated tissue, the earliest recognizable stages of muscle fiber regeneration can still be seen (fig. 32).

From this point, at which the essential gross structure and relationships of the regenerate are already established, the histological picture is characterized by rapid development of both muscle fibers and connective tissue. The first cross striations are visible on day 9 (fig. 34), but the fiber diameter and location of nuclei still reflect a very immature phase of development. The vascularization of the early regenerates is abundant, and especially in areas with more loose connective tissue than muscle, it can be plainly seen in ordinary hematoxylin and eosin preparations (fig. 35).

Midway in the second week cross striations are seen in a large percentage of the regenerated muscle fibers, and both the fiber diameter and position of nuclei attest to the rapid development (fig. 36).

The diameter of the entire regenerate is usually the smallest during the third week, for the implanted material has completely degenerated and the newly regenerating elements of both muscle and connective tissue have not attained normal adult dimensions. Figures 37 and 38 illustrate a 17 -day regenerate which is $25 \%$ the weight of the control gastrocnemius. Although a high proportion of the regenerate is composed of muscle fibers, their diameter is still quite small in comparison with that of mature fibers, and their arrangement is still somewhat more irregular than normal.

After the first month, essentially normal histological relations are established, and in some cases the general architecture 
shows a striking similarity to normal muscle. Figure 39 is an example of a 28 day regenerate which is entirely tendinous in the distal part and muscular in the proximal part. This particular regenerate even has a central band of dense connective tissue running through the area of proximal muscle fibers, much as in the normal gastrocnemius. Quite consistently, however, the regenerated Achilles tendon is proportionally larger in diameter than in the controls. This tends to decrease with increasing maturity. By this time the muscle fibers are quite mature in both individual morphology and arrangement (fig. 40). They are yet somewhat thinner than normal muscle fibers.

The regenerates are not always so well developed or proportioned as that described in the preceding paragraph, and about half of the time they remain as rather thin (4-5 $\mathrm{mm}$ ) bands of muscle fibers running parallel to the tibial nerve. In one case examined at 45 days, the regenerate was reduced to a tendinous structure with only a few scattered muscle fibers in it.

\section{DISCUSSION}

These results confirm the reports from Studitsky's laboratory (Studitsky, '59, '63; Zhenevskaya, '62) that an entire muscle in higher vertebrates can be reconstructed from an implanted mass of minced fragments. Even though the mass of such regenerates does not approach that of control muscles, the anatomical organization and relationships are usually quite normal.

In almost all details, the type of regeneration reported here differs considerably from a typical epimorphic process. This is particularly notable in the case of frogs, in which epimorphic regeneration of limbs, either natural or artificially induced, has been described by a number of authors (Polezhaev, '46; Rose, '44, '45; Singer, '54; Goode, '67). Although many of the reports on anuran limb regeneration do not include detailed histological observations, certain of these describe the presence of muscle fibers in the limb regenerates (Gidge and Rose, '44; Goode, '67). These latter authors describe dedifferentiative changes in the muscle of the limb stump, and Gidge and Rose ('44) state that the dedifferentiated muscle cells make up a portion of the blastema. In unpublished observations, this author has noted similar dedifferentiative changes in muscle fibers of large numbers of frog limbs in which some degree of regeneration has been stimulated by tissue implants. The formation of muscle fibers in frog limb regenerates appears to be subject to the same types of morphogenetic control mechanisms which operate in the regeneration of urodele limbs.

In the regeneration of whole muscles from minced fragments, a blastema appeared neither in the frog nor in the rat, and location alone would preclude any morphogenetic interactions with a wound epidermis. Particularly in the frog, occasional cells whose appearance is very similar to typical blastemal cells can be seen in the peripheral areas of early regenerates, but aggregates of such cells have not been seen. In view of the difficulty in distinguishing true blastemal cells from other primitive mesenchymal cells, it would be unwise at this time to speculate about their significance, if any, in muscle regeneration.

One rather unusual phenomenon observed in a low percentage of rat regenerates was the presence of the complete apparatus for the formation of endochondral bone, including hyaline cartilage, epiphyseal plates, spongy bone and marrow. This aspect of regeneration will be described more fully in a future publication, but it does illustrate that cells in a regenerating system such as that used in these experiments do have the capability of forming distinctly different tissue types. Although histogenesis was very complete, the gross form was nodular, and it indicates that the skeletal elements developed in an environment of very weak morphogenetic control. At present it is not possible to say whether this appearance of skeletal tissue is primarily related to the process of skeletal muscle regeneration or whether it is a secondary phenomenon such as traumatic myositis ossificans and is correlated more with a destructive rather than with a regenerative process.

The regeneration of muscle fibers follows a very similar morphological course in both the frog and the rat. The findings recorded here fit into the general pattern of muscle regeneration which has been 
pieced together by a number of investigators during the past few years. It is quite apparent at this time that the process of muscle regeneration which takes place in higher vertebrates is a fundamentally different process from that which has been described in urodele amphibians following limb amputation (Thornton, '38; Hay, '59). In amphibians nucleated fragments from damaged fibers break off from the syncytium and undergo a series of morphological transformations which render them indistinguishable from other blastemal cells.

The use of this experimental model for the purpose of producing muscle regeneration in urodeles does not seem to have been reported in the literature, but in view of the high degree of reactivity of urodele limbs after severe injury, it would not be unlikely to expect the formation of a supernumerary limb following such treatment. Perhaps the first experiments which demonstrated that minced tissue could give rise to normal regenerates in urodeles were conducted by Polezhaev ('36), who shelled out all of the tissues in axolotl limbs except for the skin, blood vessel and nerve, minced this tissue and then replaced the minced tissues inside the skin cuff. After a short healing period, the ends of the limbs were amputated, and in some cases normal regenerates resulted. Although a photomicrograph of a final regenerate is illustrated, other developmental stages are not. Thus the role of the minced tissues and their mode of development into a regenerate can not be compared with the processes described in this paper.

In mammals, damage to muscle fibers seems to be necessary for the initiation of a regenerative response. The manner by which the damage is produced does not seem to be a critical factor, for regeneration has been reported following such diverse insults as infarction (Le Gros Clark and Blomfield, '45; Godman, '57), chemical injury (Standish, '64), crushing (Allbrook et al., '66), heat (Shafiq and Gorycki, '65) and diseases such as polymyositis and muscular dystrophies (Gilbert and Hazard, '65; Shafiq et al., '67) as well as varying degrees of direct mechanical trauma ranging from simple transections (Lash et al., '57; Bintliff and
Walker, '60) to mincing (Studitsky et al., '56). Degeneration of the sarcoplasm inside of the basement membrane seems to be the earliest stage in the process, and hyaline (Zenker's), vacuolar, granular and discoid types have all been described (Allbrook et al., '66). In the present experiments the hyaline and vacuolar types were most prominent. A concomitant to sarcoplasmic degeneration seems to be a degeneration of at least a portion of the nuclei of the muscle fiber. In most reports nuclear degeneration has neither been specifically described nor extensively treated, but at least some degeneration is implied. The fragmentation of nuclear material in the frog (fig. 11) appears to be considerably more pronounced than anything described for mammalian forms.

As the sarcoplasm degenerates, macrophages and mononuclear leukocytes are seen among the sarcoplasmic fragments (Church et al., '66). During the latter phases of this degeneration, cells with swollen nuclei, prominent nucleoli and varying amounts of basophilic cytoplasm appear along the inner borders of the sarcolemmal tube. Until recently, these cells have been placed in the general category of myoblasts whose origin has been ascribed to nucleated sarcoplasmic fragments or various connective tissue cells. Since the description of satellite cells in the muscles of the frog and rat by Mauro ('61), several investigators have demonstrated that a significant percentage of the cells called myoblasts may actually be activated satellite cells (Church et al., '66; Shafiq et al., '67). Even though in the present experiments widespread degeneration of true muscle nuclei was noted, there is no evidence to indicate that some do not survive and participate in the reformation of new muscle fibers.

The individual myoblastic elements elaborate increased amounts of very basophilic cytoplasm and then fuse along the inner border of the basement membrane of the degenerated muscle fiber. Intense mitotic activity is present in such cells, and mitotic figures are often seen in cells which, by virtue of their location, seem about to fuse with the syncytium. These observations have been corroborated by others (Church et al., '66; Betz et al., '66). During this 
initial consolidation about the periphery, the core of a tube often contains varying numbers of macrophages and mononuclear leukocytes. As the early sarcoblasts mature, their nuclei begin to line up into characteristic rows, and the amount of cytoplasm increases, thus filling in the remainder of the tube. The fate of the free cells in the sarcolemmal tube is uncertain. Autoradiographic evidence of Walker ('63) indicates that these cells do not take part in actual muscle formation, but from the histological appearances of the sarcolemmal tube as it is being filled in by the developing syncytium, it is quite likely that some of these cells may be trapped within the new fiber. On the basis of morphology alone, it seems that the "halo" cells seen so often in early sarcoblasts of the frog may actually be mononuclear leukocytes which have become trapped in the expanding syncytium. The clear space around these halo cells could possibly be the product of enzymatic activity of these cells. The only mitotic figure seen in a sarcoblast in these experiments was found in one of these halo cells, but there is no morphological evidence that these cells are permanently incorporated into the regenerating fiber.

In early sarcoblasts or in myoblasts just before fusion, numerous nuclei were characterized by the deep infoldings and lobulation which have been described by the proponents of amitotic division (Altschul, '62; Studitsky, '59; Zhenevskaya, '62), but the techniques used in this study allow one to neither confirm nor deny this possibility. Autoradiographic experiments in frogs to be reported later, however, confirm the findings of Bintliff and Walker ('60) that incorporation of tritiated thymidine does not occur in nuclei already present in sarcoblasts. The differentiation of sarcoblasts into mature muscle fibers does not differ from that already described (Betz et al., '66) and warrants no further discussion here.

A number of questions must be asked with respect to development of the regenerate as a whole. One of the most intriguing concerns the ability of the minced fragments of the implanted muscle to maintain their viability during the initial few days following the operation. A sequel to this is the question of whether the im- planted cells themselves take part in regeneration or if the newly regenerated muscle possibly comes from other sources. Studitsky ('59, '63) maintains that following mincing as well as other manipulations such as tenotomy and denervation, the muscle fragments revert to a "plastic" condition, characterized by a decreased oxygen requirement and increased RNA content (Popova, '60) and from which myoblasts can develop. Although the metabolic events occurring in the newly implanted muscle fragments need much more clarification, it is apparent that despite a relatively long period of separation from a normal vascular supply, some cells survive and begin to regenerate. It was seen in both the rat and frog (figs. 14, 29) that as regeneration in peripheral areas was progressing, earlier stages of muscle regeneration began to occur in the more central portion of the implanted tissue. Histologically these areas were characterized by some very pronounced degenerative processes although some viable appearing nuclei could also be seen in most cases.

The possibility has been raised that cells other than those of the implant actually form the regenerating muscle (Litver and Dampel, '59) and that connective tissue can be induced to form muscle (Levander, '64), but a number of experiments by my associates and myself have shown that after implantation of muscle fragments devitalized by various means, no regeneration of muscle fibers occurs.

One of the questions underlying the whole problem of muscle regeneration is how the initial trauma can stimulate a regenerative process. Since the recent recognition of satellite cells and their participation in the regenerative process, the factors leading to their activation and differentiation might also be included. The trauma of the initial mincing could stimulate regeneration through the action of certain products of tissue destruction. This mechanism has often been proposed for other types of regeneration (Needham, '52; Lehmann, '61). Another distinct possibility is that the mere releasing of certain cells from their normal physical relationships with other structures stimulates a re-expression of their genetic capabilities as modulated by their new environment. 
Morphological indications of this have been described for chondrocytes by Trampusch and Harrebomée ('64), and Carison (unpublished) has observed an increased incorporation of labelled nucleotides into chondrocytes whose matrix has been eroded. Whether or not these instances are ultimately attributable to an altered chemical environment is not presently known. In the case of minced muscle implants the metabolic changes which must attend this disruption must also be suspect. Lastly there is the possibility that under normal conditions differentiation of the satellite cells may be specifically inhibited by some product of the mature muscle fiber. This type of inhibitory control of cells by more highly differentiated tissue has been suggested for a number of developing systems by Rose (' 52, ' 55 ).

The connective tissue framework upon which the muscle regeneration occurs is laid down quite early. Within just a few days, fibroblasts from both the implanted material and external sources are scattered along the fibrinous exudate which invests the implant. After both proximal and distal ends of the implant are connected to the tendon stumps, the mechanical tension applied to the implant seems to play an important role in determining both the gross morphology and histological architcture of the regenerate. Studitsky ('63) has shown that the absence of tension results in some rather profound changes in the form of the regenerate.

The role of innervation in the development of minced muscle regenerates has been extensively studied by Striganova ('61) and Zhenevskaya ('58, '62). These workers have demonstrated that early differentiation of muscle can proceed independent of a nerve supply, but that nerves are indispensable for later stages of differentiation. Without a motor supply, muscle fibers do not persist in the regenerate, and it remains a thin band of connective tissue. In the rat fully innervated regenerates develop normal looking muscle fibers and frequently demonstrate a fair degree of functional activity (Studitsky, '63). Although specific staining for nerves was not done in the present experiments, the often massive degeneration of regenerating muscle fibers early in the third week of development in the frog indicates that an adequate nerve supply was lacking. Correlated with this is the relatively small size and poor functional ability of the regenerates produced in frogs. In only two cases of these tested was any gross contractile activity obtained in frog regenerates. The rat regenerates in this series were not specifically tested for gross functional ability, but in those regenerates which appeared to have the potential to contract, gross function would have been hampered by the connective tissue adhesions between the muscular portions of the regenerate and the underlying tissues.

The differences in the rate of regeneration between the frog and rat is striking (table 1). Most processes occurred about twice as quickly in the rat. The sequence of events in muscle regeneration in Rana ridibunda (Samsonenko, '56) was quite similar to that reported here. One possible reason for the difference in rates is the temperature differential between the two species. This was somewhat over $10^{\circ}$. Hormonal or other factors may also play a role. Current experiments involving reciprocal transplants from frog to rat and vice versa may help to clarify the reason for these differences.

\section{LITERATURE CITED}

Allbrook, D. B., W. de C. Baker and W. H. Kirkaldy-Willis 1966 Muscle regeneration in experimental animals and in man. J. Bone Joint Surg., 48B: 153-169.

Altschul, R. 1962 Nuclear proliferation ("nucleosis") in damaged skeletal muscle. Zeitschr. f. Zellforsch., 56: 425-436.

Betz, E. H., H. Firket and M. Reznik 1966 Some aspects of muscle regeneration. Int. Rev. Cytol., 19: 203-227.

Bintliff, S., and B. E. Walker 1960 Radioautographic study of skeletal muscle regeneration. Am. J. Anat., 106: 233-246.

Church, J. C. T., R. F. X. Noronha and D. B. Allbrook 1966 Satellite cells and skeletal muscle regeneration. Brit. J. Surg., 53: 638-642.

Gidge, N. M., and S. M. Rose 1944 The role of larval skin in promoting limb regeneration in adult anura. J. Exp. Zool., 97: 71-93.

Gilbert, R. K., and J. B. Hazard 1965 Regeneration in human skeletal muscle. J. Path. Bact., 89: 503-512.

Godman, G. C. 1957 On the regeneration and redifferentiation of mammalian striated muscle. J. Morph., 100: 27-81.

Goode, R. P. 1967 The regeneration of limbs in adult anurans. J. Embryol. Exp. Morph., 18: $259-267$. 
Hay, E. D. 1959 Electron microscopic observations of muscle dedifferentiation in regenerating Amblystoma limbs. Devel. Biol., 1: 555-585.

Lash, J. W., H. Holtzer and H. Swift 1957 Regeneration of mature skeletal muscle. Anat. Rec., 128: 679-697.

Le Gros Clar, W. E., and L. B. Blomfield 1945 The efficiency of intramuscular anastomoses with observations on the regeneration of devascularized muscle. J. Anat., 79: 15-32.

Lehmann, F. E. 1961 Action of morphostatic substances and the role of proteases in regenerating tissues and in tumour cells. Adv. Morphogen., 1: 153-187.

Levander, G. 1964 Induction Phenomena in Tissue Regeneration. Williams and Wilkins, Baltimore, pp. 88-104.

Litver, G. M., and N. H. Dampel 1959 Concerning the regeneration of whole muscles in the rat from transplanted minced muscle tissue following their complete excision. Doklady Akad. Nauk SSSR, 125: 232-235.

Mauro, A. 1961 Satellite cell of skeletal muscle fibers. J. Biophys. Biochem. Cytol., 9: 493495.

McMinn, R. M. H. 1967 The cellular morphology of tissue repair. Int. Rev. Cytol., 22: 64-145.

Needham, A. E. 1952 Regeneration and Wound Healing. Methuen, London, pp. 59-61.

Poléjaiev, L. 1936 La valeur de la structure de l'organe et les capacités du blasteme régénératif dans la processus de la détermination du régénérat. Bull. Biol. France Belique, 70: 54-85.

Polezhaev, L. V. 1946 The loss and restoration of regenerative capacity in the limbs of tailless amphibia. Biol. Revs. 21: 141-147.

Popova, M. F. 1960 Some biochemical properties of regenerating skeletal muscle (Russian). Arkh. Anat. Gist. Embryol., 39(12): 60-64.

Rose, S. M. 1944 Methods of initiating limb regeneration in adult anura. J. Exp. Zool., 95: 149-170.

1945 The effect of $\mathrm{NaCl}$ in stimulating regeneration of limbs of frogs. J. Morph. 77: $119-139$.

1952 A hierarchy of self-limiting reactions as the basis of cellular differentiation and growth control. Am. Naturalist, 86: 337354.

1955 Specific inhibition during differentiation. Ann. N. Y. Acad. Sci., 60: 11361153.

Samsonenko, R. V. 1956 Development of muscular tissue in transplanted minced muscle in the place of completely removed muscular organs in frogs (Russian). Arkh. Anat. Gist. Embryol,, 33: 56-64.

Schotté, O. E., and J. F. Wilbur 1958 Effects of adrenal transplants upon forelimb regeneration in normal and in hypophysectomized adult frogs. J. Embryol. Exp. Morph., 6: 247-261.

Shafiq, S. A., and M. A. Gorycki 1965 Regeneration in skeletal muscle of mouse: some electron microscope observations. J. Path. Bact., 90: $123-127$.

Shafiq, S. A., M. A. Gorycki and A. T. Milhorat 1967 An electron microscopic study of regeneration and satellite cells in human muscle. Neurology, 17: 567-574.

Singer, M. 1954 Induction of regeneration of the forelimb of the postmetamorphic frog by augmentation of the nerve supply. J. Exp. Zool., 126: $419-471$.

Standish, S. M. 1964 Striated muscle regeneration after chemical injury. Arch. Path., 77: 330-339.

Striganova, A. R. 1961 Reactivity and Restorative Capacity of Denervated Muscle in Different Stages of Atrophy (Russian). Izdatel. Akad. Nauk SSSR, Moscow, 147 pp.

Studitsky, A. N. 1959 Experimental Surgery of Muscle (Russian). Izdatel. Akad. Nauk SSSR, Moscow, 338 pp.

1963 Dynamics of the development of myogenic tissue under conditions of explantation and transplantation. In: Cinemicrography in Cell Biology. Ed. by G. G. Rose. Academic Press, New York, pp. 171-200.

Studitsky, A. N., R. P. Zhenevskaya and O. N. Rumyantseva 1956 Fundamentals of the technique of restoration of muscles by means of transplantation of minced muscular tissue (Russian). Cesk. Morfol., 4(4): 331-340.

Thornton, C. S. 1938 The histogenesis of muscle in the regenerating fore limb of larval Amblystoma punctatum. J. Morph., 62: 17-47.

Trampusch, H. A. L., and A. E. Harrebomée 1964 Dedifferentiation as a prerequisite of regeneration. In: Regeneration in Animals and Related Problems. Ed. by V. Kiortsis and $H$. A. L. Trampusch. North-Holland, Amsterdam, pp. 341-374.

Walker, B. E. 1963 The origin of myoblasts and the problem of dedifferentiation. Exp. Cell. Res., 30; 80-92.

Zhenevskaya, R. P. 1958 The role played by nervous connections in the early stages of muscle regeneration (Russian). Doklady Akad. Nauk SSSR, 121: 182-185.

- 1962 Experimental histologic investigation of striated muscle tissue. Rev. Canad. Biol., 21: 457-470. 


\section{Abbreviations}

B, basophilic syncytial bands

C, implanted connective tissue

$\mathrm{M}$, implanted muscle

$\mathrm{N}$, nerve

$\mathrm{S}$, sarcoblasts

\section{PLATE 1}

\section{EXPLANATION OF FIGURES}

10 Frog regenerate (two and one-half days). The distribution and orientation of the minced muscle fibers has not changed since the time of implantation. There is little infiltration by inflammatory cells except in the most peripheral areas. A few fragments of minced connective tissue can also be seen. $22 \times$.

11 Frog regenerate ( 3 days). High power view of a muscle fiber in early stages of degeneration. Successive stages of karyorrhexis are indicated by numbers 1-4. Early cytoplasmic vacuolization has occurred, but cross striations are still visible. Outside the muscle fibers are early inflammatory cells. $440 \times$.

12 Frog regenerate (seven days). Tip of regenerate illustrating early regenerative changes in the periphery. Complete degeneration of implanted muscle fibers has occurred in peripheral areas whereas in the center they are in early stages of degeneration. In the central area, small numbers of early fibroblasts and inflammatory cells are scattered among the degenerating muscle fibers. $22 \times$.

13 Frog regenerate (seven days). Higher magnification of area bounded by rectangle in figure 12 . Except for one degenerating muscle fiber and some fragments of dense connective tissue, the cells in this figure are forming an early connective tissue matrix in which regeneration of muscle fibers will occur. Interspersed among the early fibroblasts are some erythrocytes and mononuclear leukocytes. One mitotic figure is evident (arrow). $110 \times$.

14 Frog regenerate (nine days). Low power view of entire regenerate. The outline of the regenerate illustrates that distal tapering has already occurred. Degeneration of muscle fragments is extensive distally, but in the proximal portion the center is still filled with implanted muscle fragments. Most of the distal end is composed of early connective tissue which is continuous with the cut end of the Achilles tendon. Proximally, regenerating connective tissue and early regenerating muscle occupy a thin peripheral zone in which degeneration of the original muscle fibers has occurred. $4 \times$.

15 Frog regenerate (11 days). Early stages of muscle regeneration. The sarcoplasm of the cross-sectioned muscle fibers in the lower right hand corner is just starting to degenerate. A ring of rather darkly staining nuclei surrounds most of these fibers. In the cross-sectioned fibers enclosed by the rectangle, the sarcoplasm is in a more advanced stage of degeneration, and the surrounding cells are beginning to fuse into a syncytial cuff. The longitudinally sectioned fibers at the top are bounded by syncytial basophilic cuffs. $110 \times$.

16 Frog regenerate (11 days). High power of figure 15. Cross-sectioned muscle fibers illustrating early regenerate changes. 1. Early sarcoplasmic fragmentation and invasion of macrophages. Lining the inside of the basement membrane is a discontinuous layer of flattened cells. 2. More sarcoplasmic degeneration, but few macrophages. Early fusion of myoblasts on the lower border of the fiber. 3. Further sarcoplasmic degeneration and fusion of myoblasts. 4. Over half of the circumference of the fiber is surrounded by a syncytial cuff with increasing thickness. Advanced sarcoplasmic degeneration. $440 \times$. 
Bruce M. Carlson
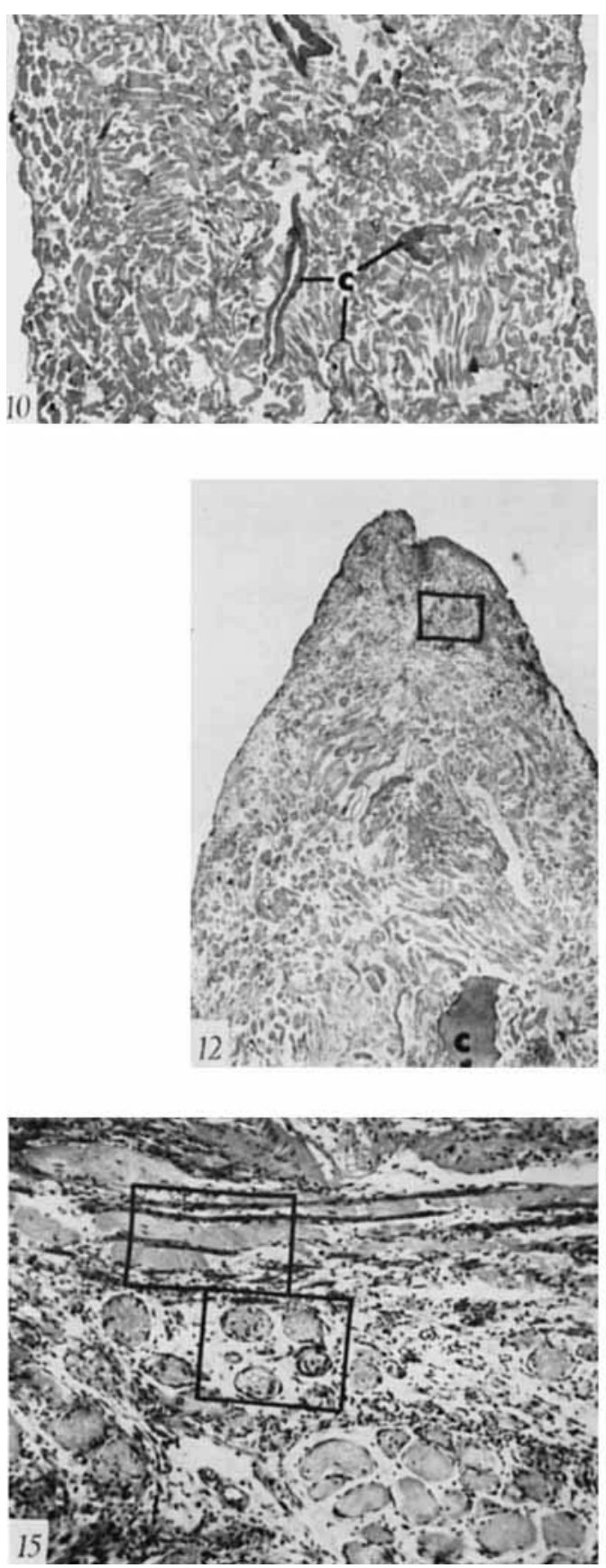
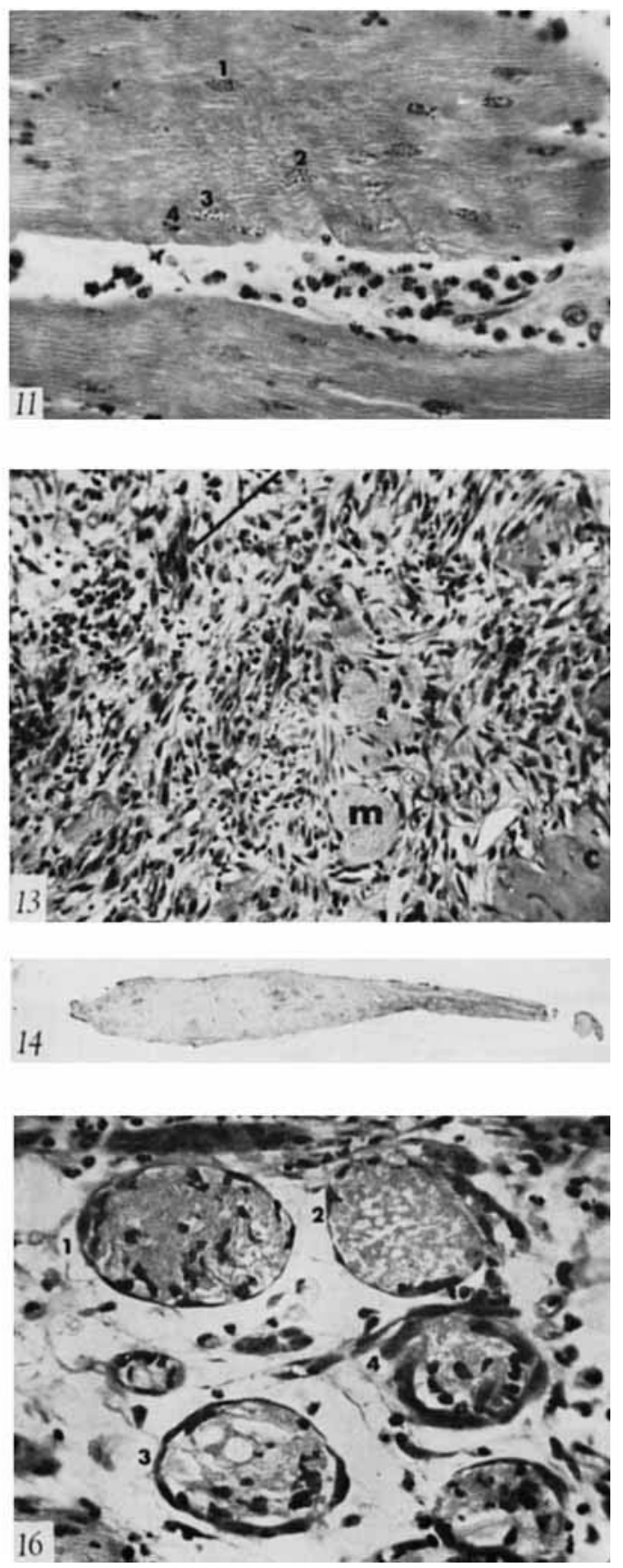


\section{PLATE 2}

\section{EXPLANATION OF FIGURES}

17 Frog regenerate ( $\mathbf{1 1}$ days). High power view of figure $\mathbf{1 5}$. Longitudinally sectioned muscle fibers with extensive basophilic syncytial bands running along the length of the fiber. "Halo" cells in the syncytium are indicated by arrows. $440 \times$.

18 Frog regenerate (11 days). Regenerate stained with Heidenhain's aniline blue for connective tissue. All newly regenerating sarcoblasts are surrounded by a thin rim of blue staining material. In the center is a muscle fiber of the original implant which has not yet degenerated. Above it is a sarcolemmal tube, completely lined by a syncytial cuff and containing macrophages but no degenerating sarcoplasm. Below the old muscle fiber are later sarcoblasts which have become solid instead of tubular as in the earlier stages. $440 \times$.

19 Frog regenerate (nine days). Multinucleated sarcoblasts. The cytoplasm is intensely basophilic, and nucleoli are prominent. $440 \times$.

20 Frog regenerate ( 13 days). Longitudinal view of sarcoblasts illustrating nuclear chains. $220 \times$.

21 Frog regenerate (15 days). Nuclear chains in the sarcoblasts are arranged in very regular rows. The cytoplasm has taken on an eosinophilic cast, and longitudinal myofibrillae are evident. $340 \times$.

22 Frog regenerate ( 18 days). The amount of sarcoplasm in the sarcoblasts is increased, and most traces of basophilia are gone. Although some of the tight nuclear chains are breaking up, the nuclei still occupy a central position in the fibers. $220 \times$. 

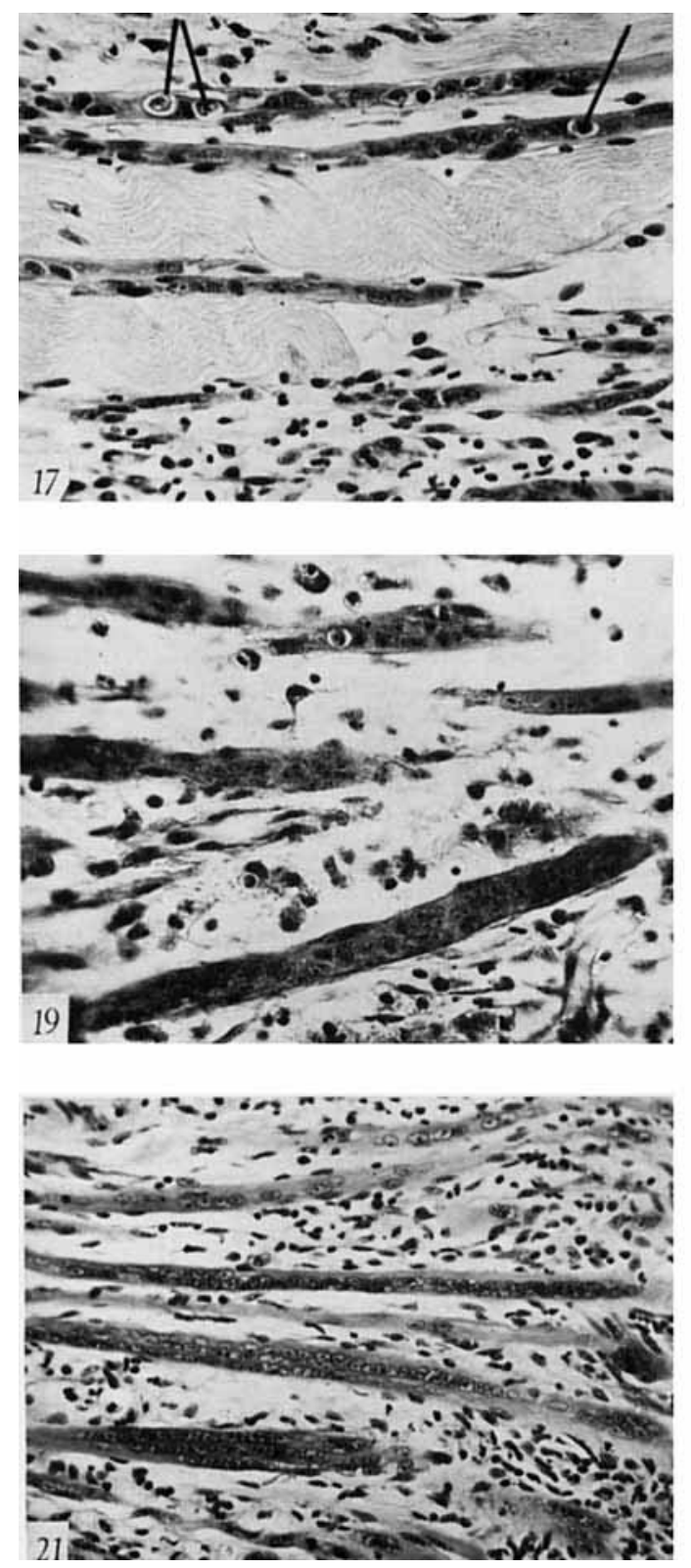
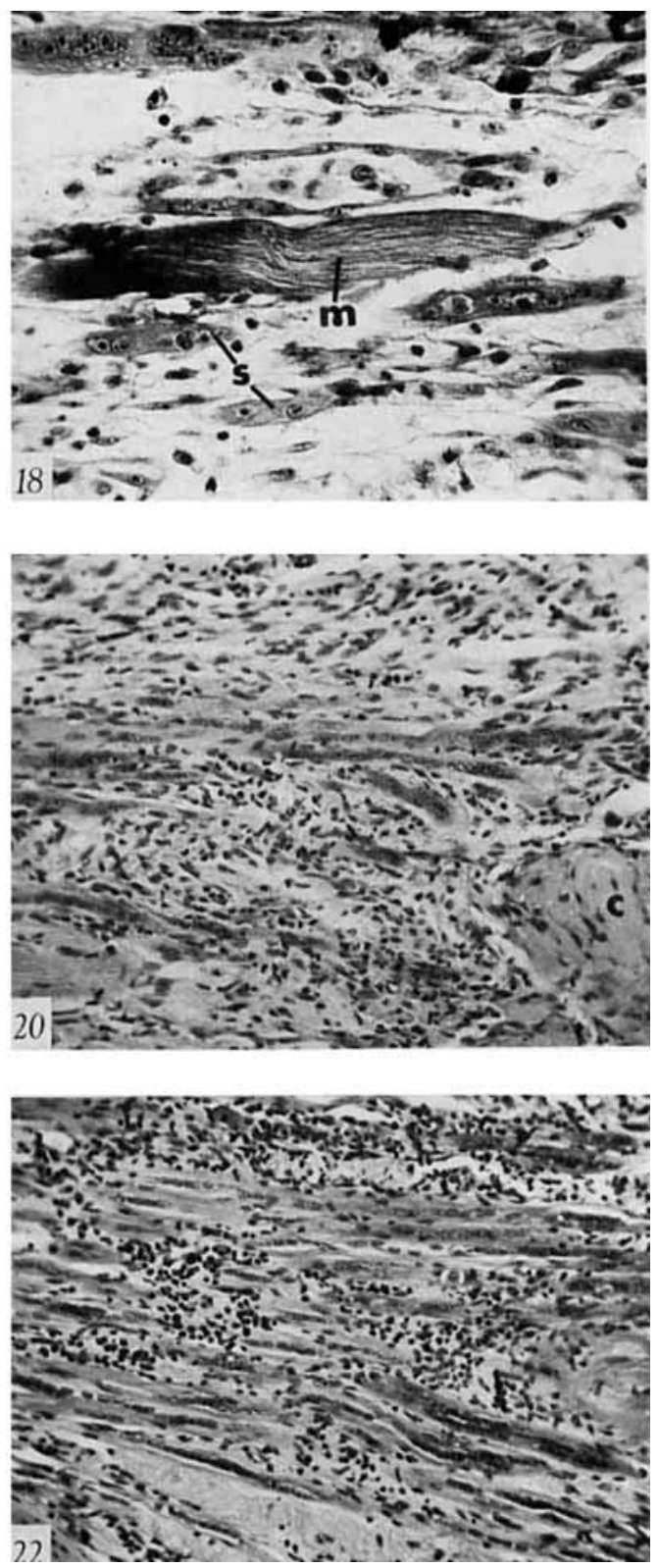
PLATE 3

\section{EXPLANATION OF FIGURES}

23 Frog regenerate (26 days). Longitudinal section of three muscle fibers. The least mature fiber is on the bottom, and the most mature is at the top. As the fibers mature, their diameter increases considerably, and the nuclei leave their central position and migrate toward the periphery. $880 \times$.

24 Frog regenerate ( 54 days). Longitudinal section through region of mature muscle fibers. The fiber orientation is parallel to the long axis of the regenerate as a whole. In some fibers traces of nuclear rows persist. Fiber diameter is somewhat less than normal. $440 \times$.

25 Frog regenerate (54 days). Longitudinal section of an area of mature regenerated muscle, but with a very irregular orientation. The fiber diameter is normal. $110 \times$.

26 Frog regenerate (54 days). Higher power view of figure 23, showing details of fiber structure and the irregularities in orientation. $440 \times$.

27 Rat regenerate (three days). Tip of regenerate. In this area the implanted muscle fibers have degenerated. In several areas early stages of muscle regeneration can be seen. The earliest stages are outlined by the rectangle. A few multinucleated sarcoblasts have already appeared. Throughout the field is a background of primitive connective tissue and phagocytic cells. $110 \times$.

28 Rat regenerate (three days). High power view of the area enclosed in the rectangle in figure 27. The sarcoplasm of the implanted muscle has disappeared, leaving the sarcolemma lined by cells (myoblasts), most of which have not fused with one another. Macrophages are present in some of the empty tubes. $440 \times$. 

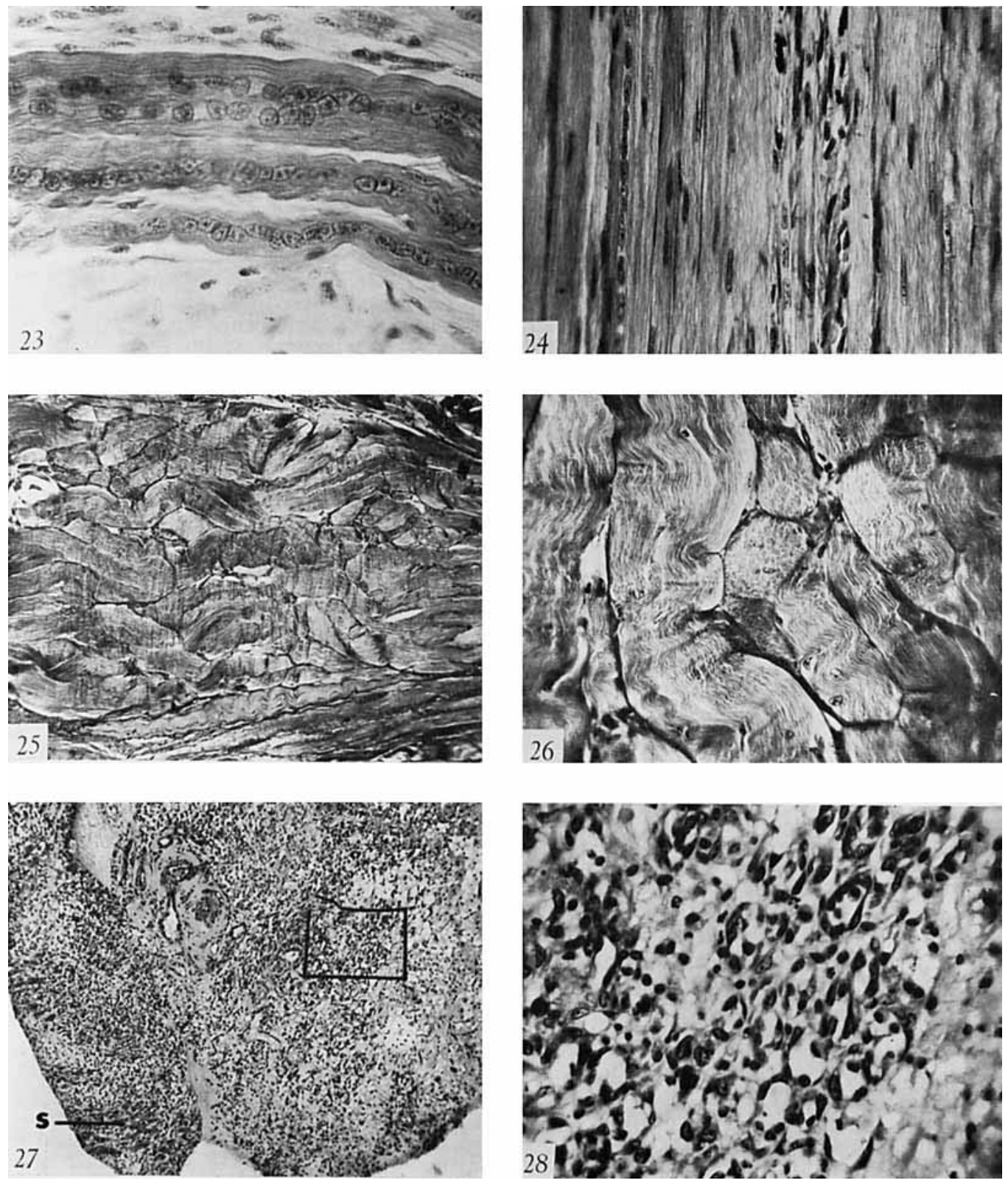


\section{PLATE 4}

EXPLANATION OF FIGURES

29 Rat regenerate (five days). Low power view through the middle portion of a regenerate. The peripheral region on either side is characterized by considerable regenerative activity. Toward the center the stages of muscle regeneration are earlier until there finally are no morphological indications of active regeneration in the central core of intact muscle fibers, which represent the initially implanted material. $20 \times$.

30 Rat regenerate (five days). Higher power view of rectangle in figure 29. This illustrates the early regenerative events taking place in the tissue located at the border between the zone of old muscle fragments and the actively regenerating periphery. As the cytoplasm of the originally implanted muscle fibers degenerates, a ring of cells surrounds the inside of the sarcolemma, $125 \times$.

31 Rat regenerate (five days). Higher power view of rectangle in figure 29 . This illustrates the more advanced stages of muscle regeneration which are found in the peripheral areas. The orientation of the sarcoblasts still corresponds more to that of the originally implanted fragments than to any lines of tension in the regenerate as a whole. $125 \times$.

32 Rat regenerate (seven days). Low power view through the middle third of the regenerate. Only a small nest of old muscle fibers remains. The more advanced regenerating muscle fibers toward the periphery are becoming oriented parallel with the longitudinal axis of the limb. $22 \times$.

33 Rat regenerate (seven days). Higher power view of area enclosed by the rectangle in figure 32 . This shows the relationships and relative proportions of the regenerating muscle and connective tissue. In some fibers aggregates of nuclei can still be seen, and in others the nuclei are beginning to disperse. $110 \times$.

34 Rat regenerate (nine days). This photomicrograph illustrates the earliest muscle fibers in which cross striations are evident. $440 \times$. 

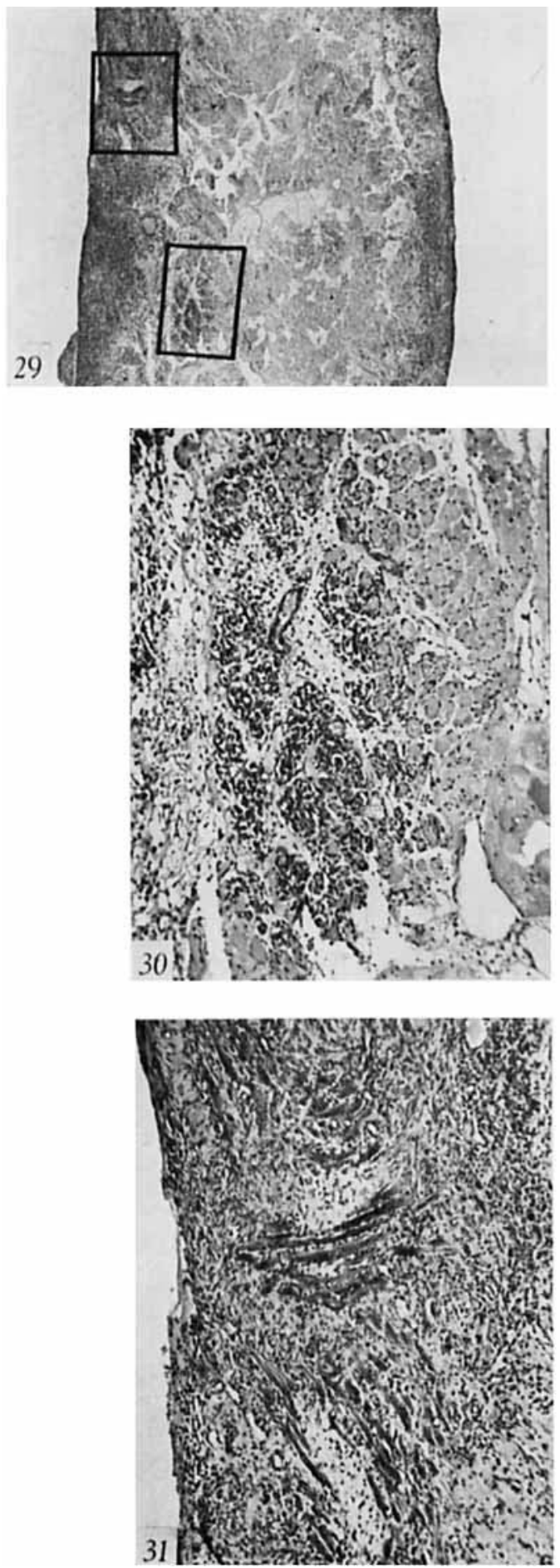
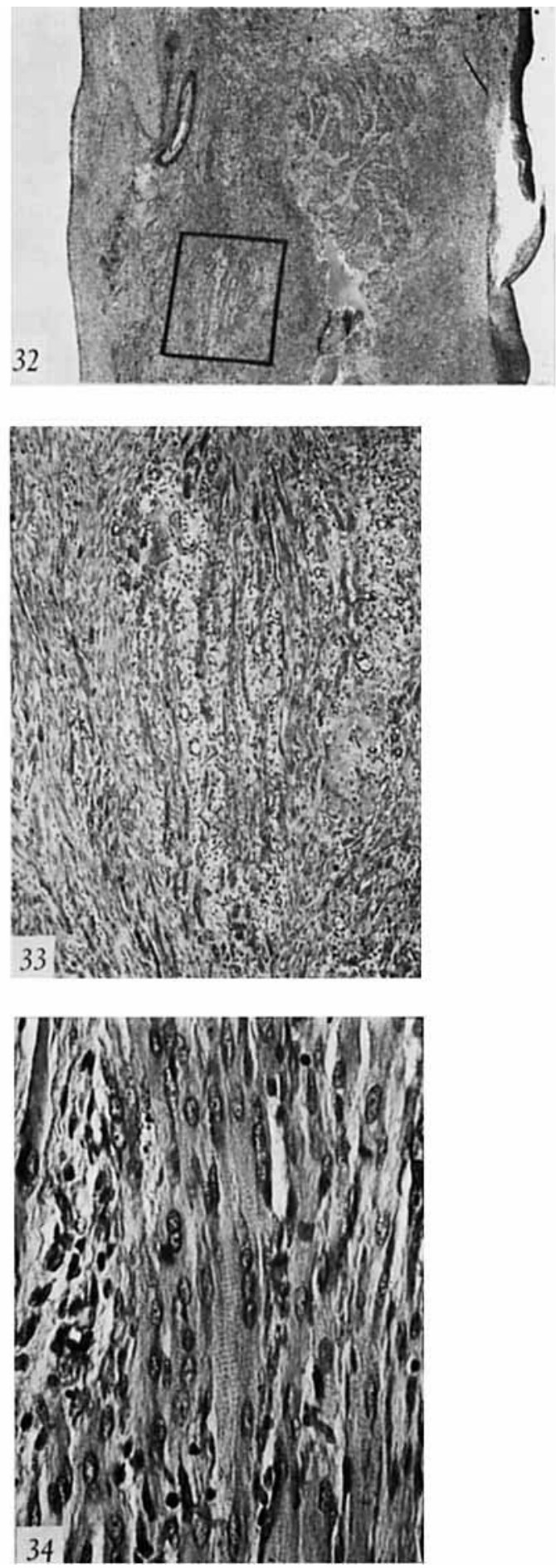
PLATE 5

EXPLANATION OF FIGURES

35 Rat regenerate (nine days). This is an area containing much connective tissue and very few regenerating muscle fibers, but it illustrates the extent of vascularization which has occurred in the early regenerate. $125 \times$.

36 Rat regenerate (11 days). Since day 9 (fig. 35 ) considerable maturation of the muscle fibers has occurred. This includes peripheral migration of nuclei, increase in fiber diameter and in the extent of cross striations. $450 \times$.

37 Rat regenerate (17 days). Low power view illustrating the architecture of the regenerate. The orientation of muscle fibers, although somewhat irregular, tends to be roughly parallel throughout the regenerate. $20 \times$.

38 Rat regenerate ( 17 days). Higher power view of the area enclosed by the rectangle in figure 37 . It illustrates the morphology and distribution of the regenerating muscle fibers. $125 \times$.

39 Rat regenerate ( 28 days). The distal half of the regenerate has tapered to a tendon composed of dense connective tissue. Most of the proximal half is composed of parallel muscle fibers, oriented in a loose bipennate arrangement around a central tendon (arrow). This arrangement is quite similar to that found in a normal gastrocnemius muscle. Heidenhain's aniline blue stain. $7.5 \times$.

40 Rat regenerate ( 28 days). Hematoxylin and eosin-stained area from another part of the regenerate shown in figure 39. This illustrates the morphology of the muscle fibers and the relatively low ratio of connective tissue to muscle. $100 \times$. 

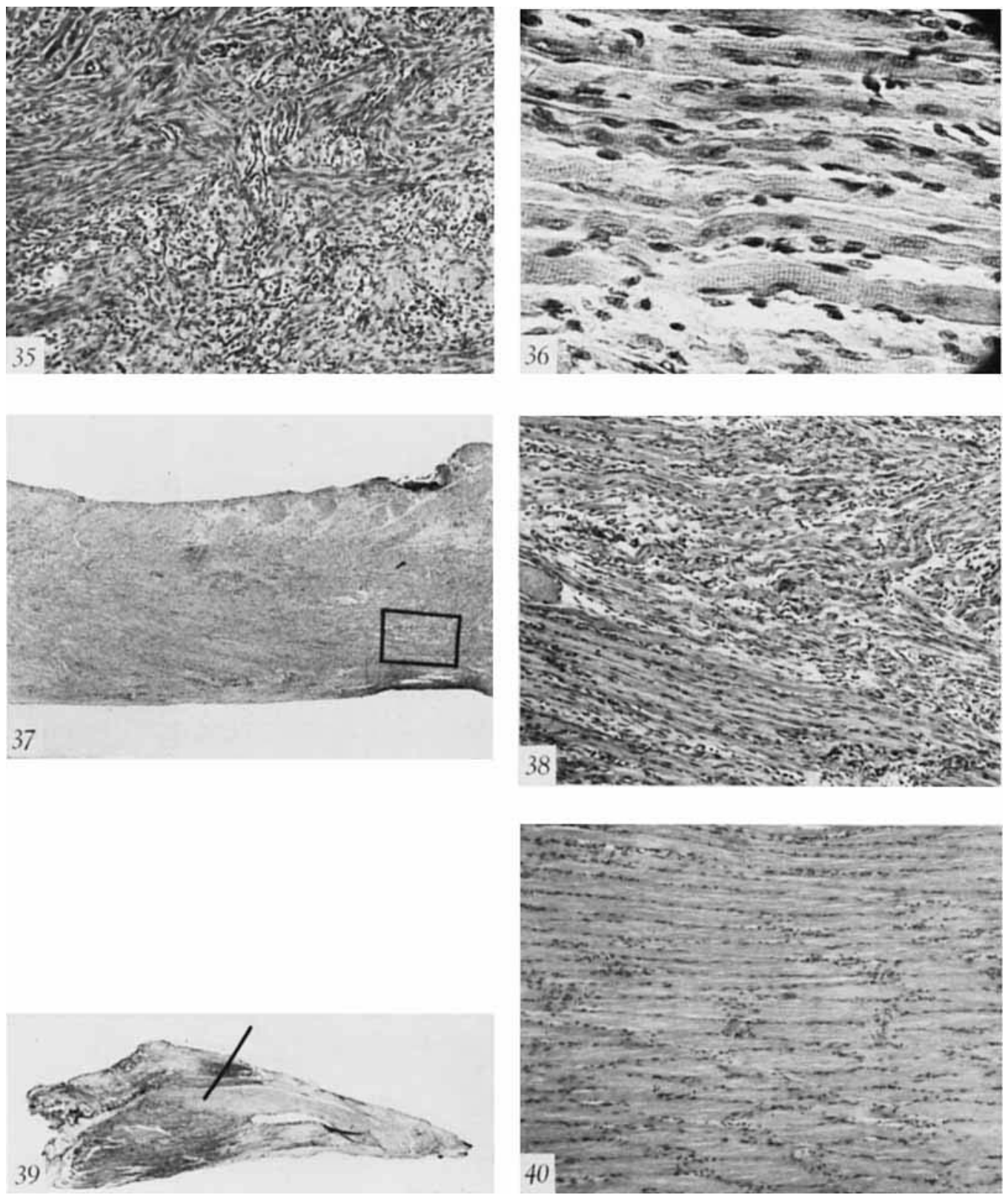